\begin{tabular}{|l|l|l|}
\hline \multicolumn{2}{|c|}{ PublisherInfo } \\
\hline \hline PublisherName & $:$ & BioMed Central \\
\hline \hline PublisherLocation & $:$ & London \\
\hline \hline PublisherImprintName & $:$ & BioMed Central \\
\hline \hline
\end{tabular}

\title{
Cytokines, septic shock and superoxide
}

\begin{tabular}{|l|l|l||}
\hline \multicolumn{2}{|c|}{ ArticleInfo } \\
\hline \hline ArticleID & $:$ & 1626 \\
\hline \hline ArticleDOI & $:$ & $10.1186 /$ rr-2001-68545 \\
\hline \hline ArticleCitationID & $:$ & 68545 \\
\hline \hline ArticleSequenceNumber & $:$ & 37 \\
\hline \hline ArticleCategory & $:$ & Paper Report \\
\hline \hline ArticleFirstPage & $:$ & 1 \\
\hline \hline ArticleLastPage & $:$ & 3 \\
\hline \hline & & RegistrationDate : 2001-9-18 \\
ArticleHistory & $:$ & Received \\
\hline \hline ArticleCopyright & $:$ 2001-2-21 \\
\hline \hline ArticleGrants & $:$ & Biomed Central Ltd2001 \\
\hline \hline ArticleContext & $:$ & 129312211 \\
\hline \hline
\end{tabular}


Undurti Das, ${ }^{\text {Aff1 }}$

Corresponding Affiliation: Aff1

Aff1 EFA Sciences LLC, Norwood, MA, USA

\section{Keywords}

Cytokines, septic shock, SOD, superoxide

\section{Context}

Although this paper was published some time ago, it is worth highlighting because it suggests new treatments for septicemia and septic shock. A major feature of septic shock is the development of hypotension and nonresponsiveness to sympathetic vasoconstrictor agents. The authors proposed that superoxide anions play a major role in the pathogenesis of this hemodynamic instability and organ dysfunction in septic shock. Hence, they studied the interaction between superoxide anions and catecholamines.

\section{Significant findings}

The authors showed that superoxide anions react with and inactivate catecholamines. This inactivation results in hyporeactivity to exogenous catecholamines. Removal of excess superoxide anions by administration of M40403 (a superoxide dimutase [SOD] mimetic) to a rat model of septic shock restored the vasopressor responses to norepinephrine and reversed the hypotension. In addition, plasma concentrations of both epinephrine and norepinephrine were significantly higher in septic rats treated with the SOD mimetic compared with untreated rats. It was also suggested that, as both epinephrine and norepinephrine inhibit the release of proinflammatory cytokines such as tumor necrosis factor-a and interleukin (IL)-1 and potentiate the release of anti-inflammatory cytokines such as IL-10, preserving the plasma levels of catecholamines is important in septic shock.

\section{Comments}

Septic shock is the most common cause of death in the intensive care units. Although it is generally believed that free radicals play an important role in the pathogenesis of septic shock, no significant 
advances in our knowledge of their role have been made that have affected management of patients. Clearly, early recognition of the development of septic shock, identifying the source of infection and administration of the relevant antibiotics and good supportive care are important. These measures alone, however, do not always help. From this study, it is apparent that excess production of superoxide anions and their ability to interact with and inactivate catecholamines, seems to be responsible for hypotension, decreased perfusion of organs and irreversible fall in blood pressure. This has also been suggested as the reason why exogenous administration of catecholamines is of little help to these patients. The ability of M40403 to reverse lipopolysaccharide-induced hypotension is particularly impressive. It remains to be seen whether M40403 or any of its analogues can indeed prevent hypotension and reverse septic shock in the patients as well.

\section{Methods}

Srague-Dawley rats, HPLC

\section{Additional information}

\section{References}

1. MacCarthur H, Westfall TC, Riley DP, Misko TP, Salvemini D: Inactivation of catecholamines by superoxide gives new insights on the pathogenesis of septic shock. Proc Nat Acad Sci USA. 2000, 97 : 9753-9758. 